\title{
Diagnostic Performance of KLCA-NCC 2018 Criteria for Hepatocellular Carcinoma Using Magnetic Resonance Imaging: A Systematic Review and Meta-Analysis
}

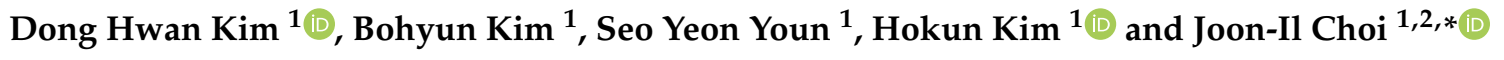 \\ 1 Department of Radiology, Seoul Saint Mary's Hospital, College of Medicine, The Catholic University of Korea, \\ 222 Banpo-daero, Seocho-gu, Seoul 06591, Korea; kimdh@catholic.ac.kr (D.H.K.); baboojum@naver.com (B.K.); \\ imseoyeon@gmail.com (S.Y.Y.); walehn@gmail.com (H.K.) \\ 2 Cancer Research Institute, College of Medicine, The Catholic University of Korea, 222 Banpo-daero, \\ Seocho-gu, Seoul 06591, Korea \\ * Correspondence: dumkycji@gmail.com; Tel.: +82-2-2258-1431; Fax: +82-2-599-6771
}

check for updates

Citation: Kim, D.H.; Kim, B.; Youn, S.Y.; Kim, H.; Choi, J.-I. Diagnostic Performance of KLCA-NCC 2018

Criteria for Hepatocellular Carcinoma Using Magnetic Resonance Imaging: A Systematic Review and Meta-Analysis. Diagnostics 2021, 11, 1763. https://doi.org/10.3390/ diagnostics 11101763

Academic Editor: Martin Mueller

Received: 23 July 2021

Accepted: 20 September 2021

Published: 25 September 2021

Publisher's Note: MDPI stays neutral with regard to jurisdictional claims in published maps and institutional affiliations.

Copyright: (C) 2021 by the authors Licensee MDPI, Basel, Switzerland. This article is an open access article distributed under the terms and conditions of the Creative Commons Attribution (CC BY) license (https:/ / creativecommons.org/licenses/by/ $4.0 /)$.

\begin{abstract}
Several imaging-based systems have been proposed for the diagnosis of hepatocellular carcinoma (HCC) using magnetic resonance imaging (MRI), reflecting geographical differences in the clinical environment for HCC. We conducted a systematic review and meta-analysis to determine the performance of the Korean Liver Cancer Association-National Cancer Center (KLCA-NCC) 2018 criteria for the MRI diagnosis of HCC. Original studies reporting the performance of the KLCA-NCC 2018 criteria for the diagnosis of HCC using MRI were identified in MEDLINE and EMBASE until 29 March 2021. The meta-analytic pooled sensitivity and specificity of the KLCA-NCC 2018 criteria for diagnosing HCC were calculated using a bivariate random-effects model. A metaregression analysis was performed to explore study heterogeneity further. Eight studies involving 1690 HCCs reported the accuracy of the KLCA-NCC 2018 imaging criteria. The pooled sensitivity and specificity of the definite HCC criteria for diagnosing HCC were 81\% (95\% confidence interval, $\left.76-85 \% ; I^{2}=86 \%\right)$ and $90 \%\left(86-93 \% ; I^{2}=23 \%\right)$, respectively. For five available studies, the pooled sensitivity and specificity of the definite HCC criteria for diagnosing HCCs smaller than $20 \mathrm{~mm}$ were $80 \%\left(72-86 \% ; I^{2}=76 \%\right)$ and $91 \%\left(86-94 \% ; I^{2}=0 \%\right)$, respectively. A considerable threshold effect with a correlation coefficient of 0.667 was observed. The results of the meta-regression analysis revealed that the accuracy of the definite HCC criteria differed significantly depending on the type of MRI contrast agent $(p=0.01)$. In conclusion, the KLCA-NCC 2018 criteria had good overall diagnostic performance in diagnosing HCC. Substantial study heterogeneity was observed for sensitivity, which was significantly influenced by the type of contrast agent and by a threshold effect.
\end{abstract}

Keywords: liver neoplasms; hepatocellular carcinoma; diagnosis; magnetic resonance imaging; meta-analysis

\section{Introduction}

Hepatocellular carcinoma (HCC) is the most common primary liver cancer and the third most frequent cause of cancer-related deaths [1,2]. HCC is the only malignancy that can be noninvasively diagnosed in at-risk patients by imaging, including multiphase computed tomography, contrast-enhanced ultrasonography, and magnetic resonance imaging (MRI), without pathological confirmation [3,4]. Therefore, accurate and consistent imagingbased diagnosis is of the utmost importance for the management of HCC. Worldwide, all imaging-based systems use a combination of arterial-phase hyperenhancement plus washout for the diagnosis of HCC [3-5]. However, geographical differences in the clinical environment and treatment practice make it challenging to establish universal guidelines for the diagnosis of HCC [3-5]. Unlike Western countries where liver transplantation is considered the only curative treatment, resection and loco-regional therapy are common curative options in Asia. 
The Korean Liver Cancer Study Group (KLCSG)-National Cancer Center (NCC) HCC practice guidelines were developed in 2003 and updated in 2009, 2014, and 2018 [5-8]. Unlike prior versions, the Korean Liver Cancer Association (KLCA, formerly KLCSG)-NCC (KLCA-NCC) 2018 practice guidelines have been revised into a nonbinary system for the imaging diagnosis of HCC [5]. The KLCA-NCC 2018 guidelines categorize each hepatic lesion according to its likelihood of HCC, i.e., indeterminate nodules, probable HCC, and definite HCC [5]. A diagnosis of the definite HCC can be made when hepatic lesions $\geq 1 \mathrm{~cm}$ show arterial-phase hyperenhancement with delayed washout after the exclusion of benign lesions showing marked T2 hyperintensity or non-HCC malignancies showing a targetoid appearance [5]. In particular, washout is possible not only during the portal phase but also during the transitional phase and hepatobiliary phase (HBP) on MRI with a hepatobiliary contrast agent [5]. The KLCA-NCC 2018 criteria were intended to improve sensitivity in the detection of early-stage HCC, which is eligible for curative treatments such as surgical resection and local ablation.

Several studies, most of which were single-center studies, reported conflicting results regarding the performance of KLCA-NCC 2018 for the diagnosis of HCC [9-13]. Given the increased attention to and use of the KLCA-NCC 2018 criteria, it is time to assess clearly the performance of KLCA-NCC 2018 in the diagnosis of HCC and to understand the causes of heterogeneity between studies. Therefore, we conducted a systematic review and meta-analysis to assess the performance of the KLCA-NCC 2018 criteria for diagnosing HCC with MRI and to determine the factors associated with study heterogeneity.

\section{Materials and Methods}

This meta-analysis was performed in compliance with the Preferred Reporting Items for Systematic Reviews and Meta-Analyses guidelines [14] and was registered in PROSPERO (ID: CRD42021269626). The following literature search, study selection, data extraction, and study quality assessments were independently conducted by two reviewers (each having $\geq 10$ years of experience in liver MRI), and any disagreements were resolved via consensus.

\subsection{Literature Search Strategy}

A literature search of the MEDLINE and EMBASE databases was conducted to identify studies investigating the diagnostic performance of the KLCA-NCC 2018 criteria for the dichotomous diagnosis of HCC based on dynamic contrast-enhanced MRI. The search queries included "Liver", "Hepatocellular carcinoma", "Korean Liver Cancer AssociationNational Cancer Center", and "KLCA-NCC". Supplementary Table S1 lists the search terms in detail. The beginning date for the search was set to 1 January 2018 to focus on original articles using the 2018 version of the KLCA-NCC. The literature search was updated until 29 March 2021. A manual evaluation of the searched articles was performed to narrow down the number of relevant articles. The search was limited to original studies on human subjects written in English. In order to expand the search, the bibliographies of articles were screened for other potentially eligible articles.

\subsection{Inclusion and Exclusion Criteria}

After duplicate articles were removed, the articles were reviewed regarding eligibility: (i) Population, patients at risk of HCC with focal hepatic lesions $(\geq 1 \mathrm{~cm}$ ); (ii) Index test, dynamic contrast-enhanced liver MRI; (iii) Reference standard, pathological diagnosis or imaging follow-up; (iv) Outcomes, sensitivity and specificity of definite HCC diagnosis according to the KLCA-NCC 2018 criteria; and (v) Study design, not limited. The exclusion criteria were as follows: (i) inclusion of a small number of patients ( $<10)$; (ii) animal studies, case reports, review articles, editorials, or scientific abstracts/conference proceedings; (iii) studies that were not within the field of interest of this study; and (iv) studies without sufficient details to construct a diagnostic 2-by-2 table of the imaging results and reference 
standard findings. Articles were first screened by titles and abstracts, and fully reviewed after the first screening.

\subsection{Data Extraction and Quality Assessment}

The following data were extracted: (i) study characteristics including authors, year of publication, and study design (prospective vs. retrospective); (ii) subject characteristics including sample size, age, sex, underlying liver disease, total number of hepatic lesions, and number of HCCs; (iii) MRI characteristics including indications for MRI, MRI scanner field strength, and type of contrast agent; (iv) image interpretation method (multiple reviewers with consensus vs. multiple independent reviewers); (v) reference standards for HCC and non-HCC; (vi) interobserver agreement ( $k$ ) for the categorization of hepatic lesions according to the KLCA-NCC 2018 criteria; and (vii) the accuracy of KLCA-NCC 2018 imaging criteria for the dichotomous diagnosis of HCC. The exact numbers of true positives, true negatives, false positives, and false negatives among hepatic lesions were extracted to determine the diagnostic accuracy of the criteria. If not distinctly mentioned, data were manually retrieved from tables and figures. If an article did not contain sufficient data, we contacted the corresponding authors by email to request additional information or clarification.

The Quality Assessment of Diagnostic Accuracy Studies (QUADAS-2) criteria [15] were used to assess the quality of the selected studies. The QUADAS-2 tool assesses study quality according to four different domains (patient selection, index test, reference standard, and flow and timing).

\subsection{Data Synthesis}

The meta-analytic pooled sensitivity and specificity were calculated using a bivariate random-effects and hierarchical summary receiver operating characteristic (HSROC) model. Heterogeneity between studies for sensitivity and specificity was assessed using the Higgins $I^{2}$ statistic $\left(I^{2}>50 \%\right.$ : substantial heterogeneity). The presence of a threshold effect was analyzed by visual assessment of the coupled forest plots of sensitivity and specificity as well as by calculating the Spearman correlation coefficient between the sensitivity and the false-positive rate (i.e., 1 -specificity) [16]. A correlation coefficient $>0.6$ was considered to represent a considerable threshold effect [16]. Deeks' funnel plot and Deeks' asymmetry test were used to assess the presence of publication bias.

A subgroup analysis was performed on studies reporting diagnostic performance for HCCs less than $20 \mathrm{~mm}$ in size and those reporting data on the "probable HCC" category in the KLCA-NCC 2018 imaging criteria. Additional subgroup analyses were performed for intra-individual comparative studies between the latest updated international guidelines. The pooled sensitivity and specificity of the KLCA-NCC 2018 criteria were compared to those of the Liver Imaging Reporting and Data System (LI-RADS) v2018, European Association for the Study of the Liver (EASL), and Asian Pacific Association for the Study of the Liver (APASL) guidelines $[4,17,18]$ using joint-model bivariate meta-regression.

In order to investigate the causes of study heterogeneity further, a meta-regression analysis was performed. The following covariates were considered: (i) study design (prospective vs. retrospective); (ii) number of patients ( $<200 \mathrm{vs.} \geq 200$ ); (iii) MRI scanner field strength ( $3.0 \mathrm{~T}$ only vs. $1.5 \mathrm{~T}$ or $3.0 \mathrm{~T}$ ); (iv) MRI contrast agent (hepatobiliary contrast agent (HBA) only vs. extracellular contrast agent (ECA) or HBA); (v) image interpretation method (multiple independent reviewers vs. multiple reviewers with consensus); (vi) reference standard for HCC (pathology only vs. pathology or imaging follow-up); and (vii) reference standard for non-HCC (pathology only vs. pathology or imaging follow-up).

Using the $\mathrm{k}$ and $95 \%$ confidence interval $(\mathrm{CI})$ reported in the individual studies, the pooled $\mathrm{k}$ with a $95 \% \mathrm{CI}$ for the categorization of hepatic lesions according to the KLCANCC 2018 criteria was calculated using the DerSimonian-Laird random-effects model. $\mathrm{K}$ was categorized according to the standards of Landis and Koch [19]. 
Stata version 16.0 (StataCorp LP, College Station, TX, USA) and R version 3.3.2 (The $\mathrm{R}$ Foundation for Statistical Computing, Vienna, Austria) were used for the analysis, with $p<0.05$ considered statistically significant.

\section{Results}

\subsection{Literature Search}

A total of 99 articles were screened after removing duplicates. Of these, 75 articles were excluded based on their titles and abstracts. Seventeen additional articles were excluded during a full-text review (Figure 1). A search of the bibliographies of the remaining articles yielded one additional eligible article. Ultimately, a total of eight eligible articles reporting the diagnostic performance of the KLCA-NCC 2018 criteria for the diagnosis of HCC were selected [9-13,20-22].

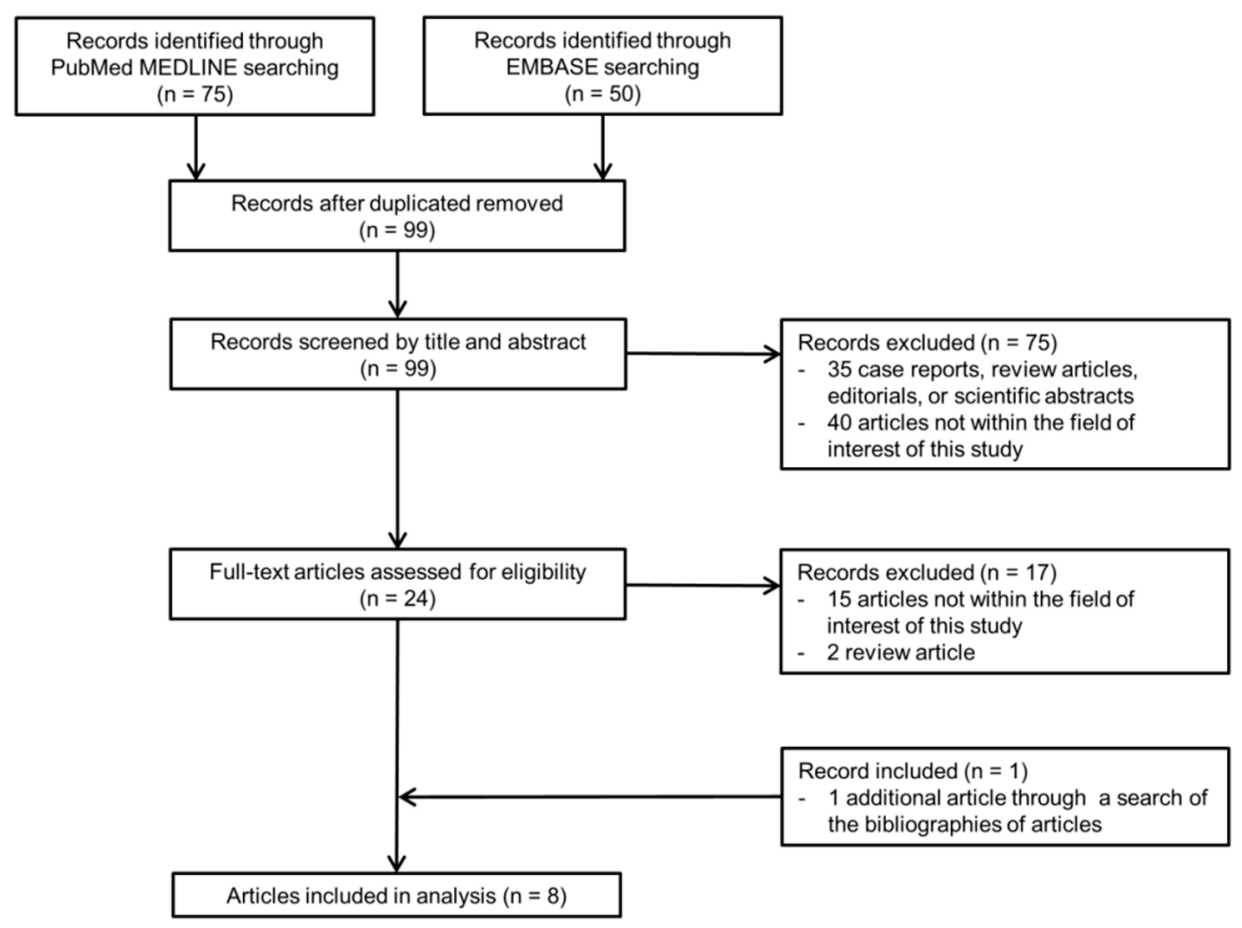

Figure 1. Flow diagram of the article selection process.

The characteristics of the final set of included articles are summarized in Table 1. Of the eight included articles, one study had a prospective design [22]. The most common underlying liver disease was hepatitis B in all eight included studies [9-13,20-22]. The indications for performing liver MRI were a pretransplant work-up in one study [10] and an evaluation of hepatic lesions detected during a surveillance examination in seven studies [9,11-13,20-22]. Two studies used only 3.0-T MRI scanners [11,20]. Six used only the HBA (gadoxetate disodium) [9-13,22], whereas two used both the HBA (gadoxetate disodium) and ECA (gadoterate meglumine, gadobutrol, or gadopentetate dimeglumine) $[20,21]$. Multiple image reviewers worked independently in five studies [10-13,22] and with consensus in three $[9,20,21]$. Six studies used pathology as the only reference standard for the diagnosis of HCC [10-13,20,21], whereas two used a combination of pathological diagnosis and imaging follow-up [9,22]. In all but one study [10], a combination of pathological diagnosis and imaging follow-up was used as a reference standard for non-HCC lesions. 
Table 1. Characteristics of the included articles.

\begin{tabular}{|c|c|c|c|c|c|c|c|c|c|c|c|c|c|}
\hline $\begin{array}{c}\text { Author } \\
\text { (Year of } \\
\text { Publication) }\end{array}$ & $\begin{array}{l}\text { Study } \\
\text { Design }\end{array}$ & $\begin{array}{l}\text { No. of } \\
\text { Patients } \\
\text { (\% Male) }\end{array}$ & $\begin{array}{l}\text { Patient } \\
\text { Age, } \\
\text { Years * }\end{array}$ & $\begin{array}{c}\text { Most Common } \\
\text { Etiology of } \\
\text { Liver Disease } \\
\text { (\% of Cirrhosis) }\end{array}$ & $\begin{array}{l}\text { No. of } \\
\text { Hepatic } \\
\text { Lesions }\end{array}$ & $\begin{array}{c}\text { No. of } \\
\text { HCC (\%) }\end{array}$ & $\underset{\text { mm }}{\text { HCC Size, }}$ & $\begin{array}{l}\text { Indication for } \\
\text { Liver MRI }\end{array}$ & $\begin{array}{c}\text { MRI } \\
\text { Magnet }\end{array}$ & $\begin{array}{c}\text { MRI } \\
\text { Contrast } \\
\text { Agent (\%) }\end{array}$ & $\begin{array}{c}\text { Image } \\
\text { Reviewer }\end{array}$ & $\begin{array}{l}\text { Reference } \\
\text { Standard } \\
\text { for HCC }\end{array}$ & $\begin{array}{c}\text { Reference } \\
\text { Standard } \\
\text { for } \\
\text { Non-HCC }\end{array}$ \\
\hline $\begin{array}{c}\text { Byun J (2020) } \\
\text { [9] }\end{array}$ & Retrospective & $400(80.5)$ & 59.7 & $\begin{array}{l}\text { Hepatitis B } \\
\text { virus (NA) }\end{array}$ & 493 & 399 (80.9) & $\begin{array}{l}21 \text { (range, } \\
10-30)\end{array}$ & $\begin{array}{c}\text { Evaluation of } \\
\text { hepatic nodule } \\
\text { detected during } \\
\text { surveillance }\end{array}$ & $1.5-$ or $3.0-\mathrm{T}$ & HBA & $\begin{array}{l}\text { Multiple } \\
\text { reviewers } \\
\text { with } \\
\text { consensus }\end{array}$ & $\begin{array}{l}\text { Pathology } \\
\text { or imaging } \\
\text { follow-up }\end{array}$ & $\begin{array}{c}\text { Pathology } \\
\text { or imaging } \\
\text { follow-up }\end{array}$ \\
\hline $\begin{array}{c}\text { Jeon SK (2020) } \\
{[10]}\end{array}$ & Retrospective & $81(82.7)$ & $54.1 \pm 8.7$ & $\begin{array}{l}\text { Hepatitis B } \\
\text { virus (NA) }\end{array}$ & 137 & 107 (78.1) & $20 \pm 16$ & $\begin{array}{l}\text { Pretransplant } \\
\text { work-up }\end{array}$ & $1.5-$ or $3.0-\mathrm{T}$ & HBA & $\begin{array}{l}\text { Multiple in- } \\
\text { dependent } \\
\text { reviewers }\end{array}$ & $\begin{array}{l}\text { Pathology } \\
\text { only }\end{array}$ & $\begin{array}{c}\text { Pathology } \\
\text { only }\end{array}$ \\
\hline $\begin{array}{c}\text { Lee S (2020) } \\
{[20]}\end{array}$ & Retrospective & $273(68.9)$ & $57.3 \pm 9.5$ & $\begin{array}{l}\text { Hepatitis B } \\
\text { virus (54.9) }\end{array}$ & 352 & $263(74.7)$ & $\begin{array}{c}24 \text { (range, } \\
15-34)\end{array}$ & $\begin{array}{c}\text { Evaluation of } \\
\text { hepatic nodule } \\
\text { detected during } \\
\text { surveillance }\end{array}$ & $3.0-\mathrm{T}$ & $\begin{array}{l}\text { ECA or } \\
\text { HBA }\end{array}$ & $\begin{array}{l}\text { Multiple } \\
\text { reviewers } \\
\text { with } \\
\text { consensus }\end{array}$ & $\begin{array}{l}\text { Pathology } \\
\text { only }\end{array}$ & $\begin{array}{l}\text { Pathology } \\
\text { or imaging } \\
\text { follow-up }\end{array}$ \\
\hline $\begin{array}{l}\text { Lee S }(2020) \\
\quad(2)[21]\end{array}$ & Retrospective & $142(73.2)$ & $57.2 \pm 9.9$ & $\begin{array}{l}\text { Hepatitis B } \\
\text { virus (NA) }\end{array}$ & 183 & 149 (81.4) & $30.2 \pm 23.9$ & $\begin{array}{l}\text { Evaluation of } \\
\text { hepatic nodule } \\
\text { detected during } \\
\text { surveillance }\end{array}$ & $1.5-$ or $3.0-\mathrm{T}$ & $\begin{array}{l}\text { ECA or } \\
\text { HBA }\end{array}$ & $\begin{array}{l}\text { Multiple } \\
\text { reviewers } \\
\text { with } \\
\text { consensus }\end{array}$ & $\begin{array}{l}\text { Pathology } \\
\text { only }\end{array}$ & $\begin{array}{c}\text { Pathology } \\
\text { or imaging } \\
\text { follow-up }\end{array}$ \\
\hline $\begin{array}{c}\text { Hwang SH } \\
\text { (2021) [11] }\end{array}$ & Retrospective & $177(80.2)$ & 58 & $\begin{array}{l}\text { Hepatitis B } \\
\text { virus (NA) }\end{array}$ & 241 & 149 (61.8) & 20, median & $\begin{array}{l}\text { Evaluation of } \\
\text { hepatic nodule } \\
\text { detected during } \\
\text { surveillance }\end{array}$ & $3.0-\mathrm{T}$ & HBA & $\begin{array}{l}\text { Multiple in- } \\
\text { dependent } \\
\text { reviewers }\end{array}$ & $\begin{array}{l}\text { Pathology } \\
\text { only }\end{array}$ & $\begin{array}{l}\text { Pathology } \\
\text { or imaging } \\
\text { follow-up }\end{array}$ \\
\hline $\begin{array}{c}\text { Kang HJ } \\
\text { (2021) [22] }\end{array}$ & Prospective & 103 (78.6) & 63.1 & $\begin{array}{l}\text { Hepatitis B } \\
\text { virus (43.7) }\end{array}$ & 103 & 79 (76.7) & $\begin{array}{l}28.2 \text { (range, } \\
11-114)\end{array}$ & $\begin{array}{l}\text { Evaluation of } \\
\text { hepatic nodule } \\
\text { detected during } \\
\text { surveillance }\end{array}$ & $1.5-$ or $3.0-\mathrm{T}$ & HBA & $\begin{array}{l}\text { Multiple in- } \\
\text { dependent } \\
\text { reviewers }\end{array}$ & $\begin{array}{l}\text { Pathology } \\
\text { or imaging } \\
\text { follow-up }\end{array}$ & $\begin{array}{c}\text { Pathology } \\
\text { or imaging } \\
\text { follow-up }\end{array}$ \\
\hline $\begin{array}{l}\text { Lee SM (2021) } \\
{[13]}\end{array}$ & Retrospective & $387(78.8)$ & $59 \pm 10$ & $\begin{array}{l}\text { Hepatitis B } \\
\text { virus (74.2) }\end{array}$ & 422 & $234(55.5)$ & $\begin{array}{l}32 \pm 21 \text { (all } \\
\text { lesions) }\end{array}$ & $\begin{array}{l}\text { Evaluation of } \\
\text { hepatic nodule } \\
\text { detected during } \\
\text { surveillance }\end{array}$ & $1.5-$ or $3.0-\mathrm{T}$ & HBA & $\begin{array}{l}\text { Multiple in- } \\
\text { dependent } \\
\text { reviewers }\end{array}$ & $\begin{array}{l}\text { Pathology } \\
\text { only }\end{array}$ & $\begin{array}{l}\text { Pathology } \\
\text { or imaging } \\
\text { follow-up }\end{array}$ \\
\hline $\begin{array}{l}\text { Park SH } \\
(2021)[12]\end{array}$ & Retrospective & $386(76.2)$ & $\begin{array}{c}56.4 \pm \\
10.3\end{array}$ & $\begin{array}{l}\text { Hepatitis B } \\
\text { virus (70.2) }\end{array}$ & 447 & $310(69.4)$ & $18.6 \pm 6.3$ & $\begin{array}{l}\text { Evaluation of } \\
\text { hepatic nodule } \\
\text { detected during } \\
\text { surveillance }\end{array}$ & $1.5-$ or $3.0-\mathrm{T}$ & HBA & $\begin{array}{l}\text { Multiple in- } \\
\text { dependent } \\
\text { reviewers }\end{array}$ & $\begin{array}{l}\text { Pathology } \\
\text { only }\end{array}$ & $\begin{array}{l}\text { Pathology } \\
\text { or imaging } \\
\text { follow-up }\end{array}$ \\
\hline
\end{tabular}

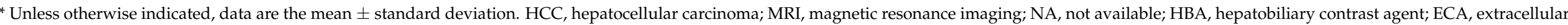
contrast agent. 


\subsection{Quality Assessment}

The quality of the included articles is summarized in Supplementary Figure S1. In the flow and timing domain, one study had a high risk of bias due to an inappropriate interval between the index test and the reference standard (i.e., within 180 days) and did not consistently use the same reference standard [11]. In addition, three studies showed an unclear risk of bias because the interval between the index test and reference standard was not specified $[12,13,22]$. In the patient selection domain, one study showed a high risk of bias because it enrolled only patients who underwent liver transplantation [10]. In the reference standard domain, two studies left it unclear whether the reference standard results were interpreted without knowledge of the index test results $[9,22]$.

\subsection{Performance of the KLCA-NCC 2018 Criteria in Diagnosing HCC}

There were 1690 HCCs out of 2378 hepatic lesions in eight studies [9-13,20-22]. The meta-analytic summary sensitivity and specificity of definite HCC criteria were $81 \%$ (95\% CI, 76-85\%; $\left.I^{2}, 86 \%\right)$ and $90 \%\left(95 \%\right.$ CI, 86-93\%; $\left.I^{2}, 23 \%\right)$, respectively (Table 2 and Figure 2A). The HSROC curve with $95 \%$ confidence and prediction regions (Figure 2B) showed a large difference between the two regions, indicating considerable heterogeneity between studies. The area under the summary receiver operating characteristic curve was 0.93 (95\% CI, 0.90-0.95). Visual analysis of the coupled forest plots of sensitivity and specificity indicated the presence of a threshold effect (Figure 2A), as did the corresponding correlation coefficient of 0.667 between the sensitivity and the false-positive rate $(p=0.07)$. There was no significant publication bias across the studies $(p=0.85$; Supplementary Figure S2).

Five studies (478 HCCs out of 870 lesions) reported the performance of the definite HCC criteria in diagnosing HCCs less than $20 \mathrm{~mm}$ in size $[9,10,12,13,20]$, showing a pooled sensitivity and specificity of $80 \%\left(95 \% \mathrm{CI}, 72-86 \% ; \mathrm{I}^{2}=76 \%\right)$ and $91 \%(95 \% \mathrm{CI}, 86-94$; $\left.I^{2}=0 \%\right)$, respectively. Three studies (646 HCCs out of 957 lesions) reported the performance of the "probable HCC" category for diagnosing HCC $[13,20,21]$. The meta-analytic pooled sensitivity and specificity for a combination of the definite and probable HCC (definite/probable HCC) categories were 87\% (95\% CI, 81-92\%) and 87\% (95\% CI, 81-93\%), respectively. 
Table 2. Diagnostic performance of definite HCC criteria of KLCA-NCC 2018 in diagnosing HCC.

\begin{tabular}{|c|c|c|c|c|c|c|c|c|c|c|c|c|c|}
\hline \multirow{3}{*}{ Author } & \multirow{3}{*}{$\begin{array}{c}\text { Total Number } \\
\text { of Nodules }\end{array}$} & \multicolumn{6}{|c|}{ For All HCCs } & \multicolumn{6}{|c|}{ For HCCs Smaller than $20 \mathrm{~mm}$} \\
\hline & & \multicolumn{4}{|c|}{ Number of Lesions } & \multirow{2}{*}{$\begin{array}{c}\text { Sensitivity } \\
\text { (95\% CI) }\end{array}$} & \multirow{2}{*}{$\begin{array}{c}\text { Specificity } \\
(95 \% \text { CI) }\end{array}$} & \multicolumn{4}{|c|}{ Number of Lesions } & \multirow{2}{*}{$\begin{array}{c}\text { Sensitivity } \\
(95 \% \text { CI })\end{array}$} & \multirow{2}{*}{$\begin{array}{c}\text { Specificity } \\
(95 \% \text { CI) }\end{array}$} \\
\hline & & $T P$ & $F P$ & $F N$ & $T N$ & & & $T P$ & $F P$ & $F N$ & $T N$ & & \\
\hline Byun J (2020) [9] & 493 & 335 & 16 & 64 & 78 & $84 \%(80,87)$ & $83 \%(74,90)$ & 136 & 10 & 27 & 60 & $83 \%(77,89)$ & $86 \%(75,93)$ \\
\hline Jeon SK (2020) [10] & 137 & 76 & 3 & 31 & 27 & $71 \%(61,79)$ & $90 \%(73,98)$ & 39 & 2 & 21 & 21 & $65 \%(52,77)$ & $91 \%(72,99)$ \\
\hline Lee S (2020) [20] & 352 & 202 & 5 & 61 & 84 & $77 \%(71,82)$ & $94 \%(87,98)$ & 57 & 2 & 22 & 51 & $72 \%(61,82)$ & $96 \%(87,100)$ \\
\hline Lee S (2020) (2) [21] & 183 & 97 & 1 & 52 & 33 & $65 \%(57,73)$ & $97 \%(85,100)$ & & & & & & \\
\hline Hwang SH (2021) [11] & 241 & 127 & 11 & 22 & 81 & $85 \%(79,91)$ & $88 \%(80,94)$ & & & & & & \\
\hline Kang HJ (2021) [22] & 103 & 68 & 3 & 11 & 21 & $86 \%(76,93 \%)$ & $88 \%(68,97)$ & & & & & & \\
\hline Lee SM (2021) [13] & 422 & 204 & 26 & 30 & 162 & $87 \%(82,91)$ & $86 \%(80,91 \%)$ & 40 & 14 & 5 & 114 & $89 \%(76,96)$ & $89 \%(82,94)$ \\
\hline Park SH (2021) [12] & 447 & 267 & 16 & 43 & 121 & $86 \%(82,90)$ & $88 \%(82,93 \%)$ & 111 & 12 & 20 & 106 & $85 \%(77,90)$ & $90 \%(83,95)$ \\
\hline \multicolumn{6}{|c|}{ Higgins $I^{2}$ for study heterogeneity } & $86 \%$ & $23 \%$ & & & & & $76 \%$ & $0 \%$ \\
\hline \multicolumn{6}{|c|}{ Meta-analytic summary estimate using the bivariate model } & $81 \%(76,85)$ & $90 \%(86,93)$ & & & & & $80 \%(72,86) *$ & $91 \%(86,94) *$ \\
\hline
\end{tabular}

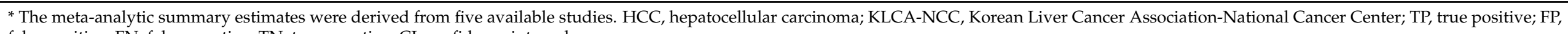
false positive; FN, false negative; TN, true negative; $\mathrm{CI}$, confidence interval. 


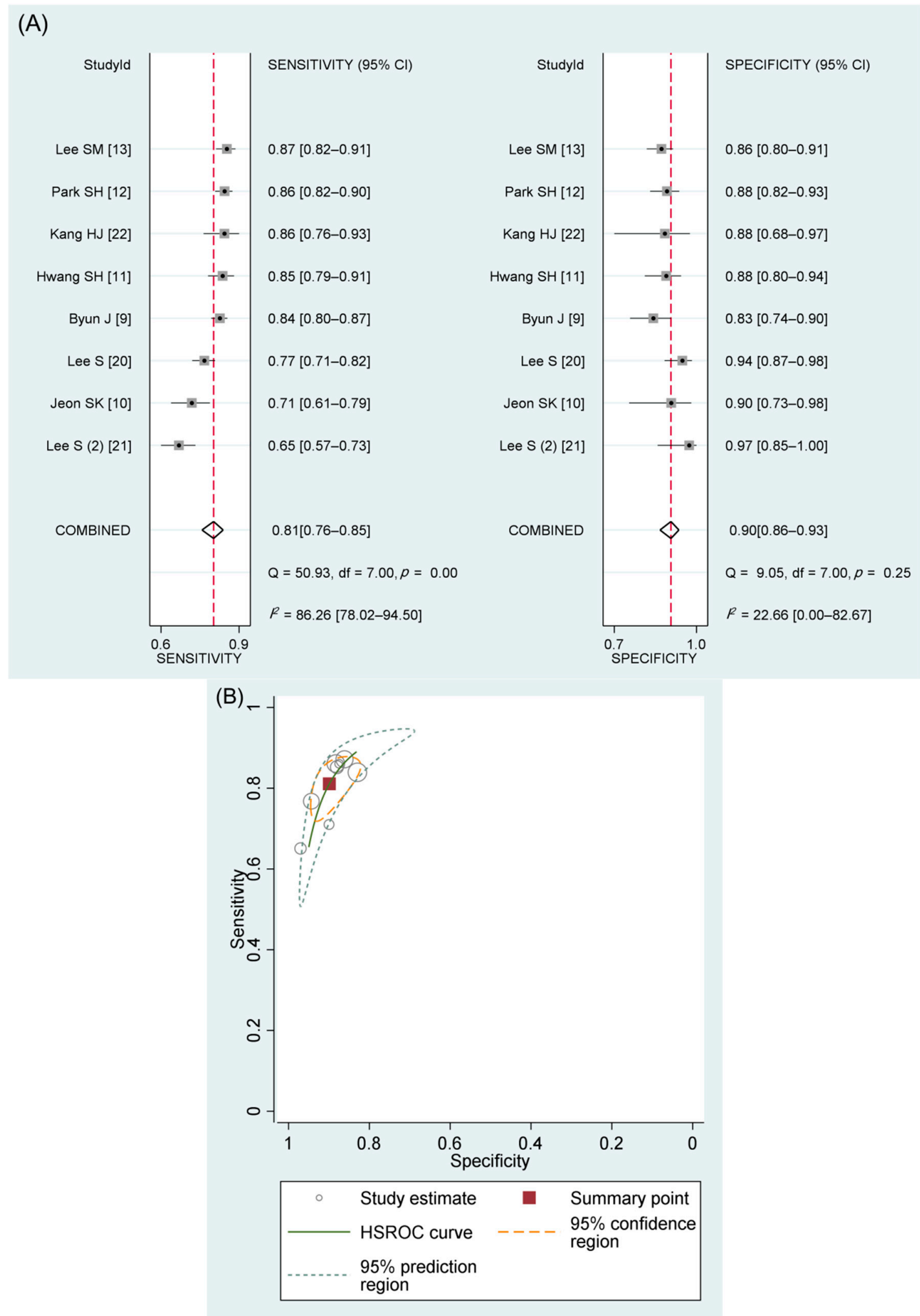

Figure 2. Coupled forest plots and HSROC curve for definite HCC of KLCA-NCC 2018 imaging criteria. (A) Coupled forest plots of the sensitivity and specificity of definite HCC for the diagnosis of HCC. (B) HSROC curve for the accuracy of definite HCC for the diagnosis of HCC. HSROC, hierarchical summary receiver operating characteristic; HCC, hepatocellular carcinoma; KLCA-NCC, Korean Liver Cancer Association-National Cancer Center; CI, confidence interval; df, degrees of freedom. 


\subsection{Subgroup Analysis Comparing the Performance of Different International Guidelines}

Six studies compared the diagnostic performance of the KLCA-NCC 2018 definite HCC criteria and the LI-RADS category 5 (LR-5) criteria [9-13,20]. The definite HCC criteria of KLCA-NCC 2018 demonstrated a significantly higher pooled sensitivity than the LR-5 criteria ( $82 \%(95 \%$ CI, 77-88\%) vs. $65 \%(95 \%$ CI, 57-74\%)) but a significantly lower pooled specificity $(89 \%(95 \%$ CI, $85-92 \%)$ vs. $95 \%(95 \%$ CI, $92-97 \%))(p=0.01)$. Five studies compared the diagnostic performance of the KLCA-NCC 2018 definite HCC criteria and the EASL guideline [9-12,22]. A similar trend was observed, where the pooled sensitivity of the definite HCC criteria of KLCA-NCC 2018 was significantly higher than that of EASL guideline $(83 \%(95 \% \mathrm{CI}, 78-88 \%)$ vs. $60 \%(95 \% \mathrm{CI}, 52-67 \%))$, but the pooled specificity was significantly lower $(87 \%(95 \%$ CI, $83-90 \%)$ vs. $93 \%(95 \%$ CI, $90-96 \%))(p<0.01)$. Four studies compared the diagnostic performance of the KLCA-NCC 2018 definite HCC criteria and the APASL guideline [9-12]. The definite HCC criteria of KLCA-NCC 2018 showed a significantly lower pooled sensitivity than the APASL guideline (83\% (95\% CI, 77-88\%) vs. $87 \%(95 \%$ CI, $82-91 \%)$ ) but a higher pooled specificity $(87 \%$ (95\% CI, $83-90 \%)$ vs. $80 \%$ $(95 \% \mathrm{CI}, 76-85 \%))(p=0.04)$.

\subsection{Meta-Regression Analysis}

The results of the meta-regression analysis for the diagnostic performance of KLCANCC 2018 are summarized in Table 3. Among the eight included covariates, the type of MRI contrast agent $(p=0.01)$ was the only factor that significantly influenced study heterogeneity. Studies using only HBA showed significantly higher sensitivity than those using either ECA or HBA ( $84 \%$ vs. $72 \%$ ) but showed significantly lower specificity $(87 \%$ vs. $95 \%$ ). The other covariates were not significantly associated with study heterogeneity.

Table 3. Results of meta-regression analysis of the accuracy of definite HCC criteria of KLCA-NCC 2018 for diagnosing HCC.

\begin{tabular}{|c|c|c|c|c|}
\hline \multirow[b]{2}{*}{ Covariates } & \multirow[b]{2}{*}{ Subgroup } & \multicolumn{2}{|c|}{ Meta-Analytic Summary Estimate } & \multirow[b]{2}{*}{$p$-Value } \\
\hline & & Sensitivity $(95 \% \mathrm{CI})$ & Specificity $(95 \% \mathrm{CI})$ & \\
\hline \multirow[t]{2}{*}{ Study design } & Prospective $(n=1)$ & $86 \%(74,98)$ & $88 \%(72,100)$ & 0.74 \\
\hline & Retrospective $(n=7)$ & $80 \%(75,86)$ & $90 \%(86,94)$ & \\
\hline Number of patients & $<200(n=4)$ & $77 \%(70,85)$ & $91 \%(86,96)$ & 0.42 \\
\hline MRI scanner field & $3.0 \mathrm{~T}$ only $(n=2)$ & $81 \%(72,91)$ & $91 \%(86,97)$ & 0.70 \\
\hline strength & $1.5 \mathrm{~T}$ or $3.0 \mathrm{~T}(n=6)$ & $81 \%(75,87)$ & $89 \%(85,93)$ & \\
\hline \multirow[t]{2}{*}{ MRI contrast agent } & Hepatobiliary contrast agent $(n=6)$ & $84 \%(80,87)$ & $87 \%(84,90)$ & 0.01 \\
\hline & $\begin{array}{l}\text { Extracellular or hepatobiliary contrast } \\
\text { agent }(n=2)\end{array}$ & $72 \%(63,80)$ & $95 \%(91,99)$ & \\
\hline Image interpretation & Multiple independent reviewers $(n=5)$ & $84 \%(79,89)$ & $89 \%(84,93)$ & 0.27 \\
\hline method & Multiple reviewers with consensus $(n=3)$ & $76 \%(69,84)$ & $92 \%(86,97)$ & \\
\hline Reference standard & Pathology only $(n=6)$ & $80 \%(74,86)$ & $91 \%(87,95)$ & 0.25 \\
\hline for HCC & Pathology or imaging follow-up $(n=2)$ & $85 \%(76,93)$ & $84 \%(74,93)$ & \\
\hline Reference standard & Pathology only $(n=1)$ & $71 \%(54,88)$ & $90 \%(77,100)$ & 0.35 \\
\hline for non-HCC & Pathology or imaging follow-up $(n=7)$ & $82 \%(78,87)$ & $90 \%(86,94)$ & \\
\hline
\end{tabular}

HCC, hepatocellular carcinoma; KLCA-NCC, Korean Liver Cancer Association-National Cancer Center; CI, confidence interval; MRI, magnetic resonance imaging.

\subsection{Interobserver Agreement for Categorization}

Five included studies with a total of 1352 hepatic lesions (911 HCCs) reported the interobserver agreement for the categorization of lesions according to the KLCA-NCC 2018 criteria using MRI $[10,11,13,20,21]$. There was substantial or almost perfect agreement between image reviewers, with $\mathrm{k}$ values ranging from 0.62 to 0.94 . For available studies reporting the $\mathrm{k}$ and standard variance (i.e., the $\mathrm{CI}$ of $\mathrm{k}$ ) $[10,20,21]$, the pooled $\mathrm{k}$ was 0.90 $\left(95 \%\right.$ CI, 0.84-0.96; $I^{2}=78 \%$; Supplementary Figure S3).

\section{Discussion}

Our meta-analysis showed that the pooled sensitivity and specificity of the KLCANCC 2018 imaging criteria for definite HCC were 81\% (95\% CI, 76-85\%) and 90\% (95\% CI, 
86-93\%), respectively. For HCCs smaller than $20 \mathrm{~mm}$, the performance of these standards was comparable to its performance for all HCCs. For the definite/probable HCC categories, the meta-analytic summary sensitivity and specificity were $87 \%(95 \% \mathrm{CI}, 81-92 \%)$ and $87 \%$ (95\% CI, 81-93\%), respectively. Substantial study heterogeneity was noted in sensitivity, with the type of MRI contrast agent and the threshold effect being significantly associated with study heterogeneity.

This study demonstrated that the definite HCC criteria of KLCA-NCC 2018 had good overall diagnostic performance for the MRI diagnosis of HCC, with substantial to almost perfect interobserver agreement. In addition, the subgroup analyses revealed that the pooled sensitivity of the definite HCC criteria of KLCA-NCC 2018 was significantly higher than that of the LR-5 or EASL guideline, consistent with recent comparative studies [9-13,20,22]. In line with previous studies [23,24], the high sensitivity of KLCANCC 2018 is largely attributable to the extended washout time, which extends to the transitional phase and the HBP. Since HBP signal intensity alterations precede typical vascular profile changes during hepatocellular carcinogenesis [25], more cases of early HCC can be diagnosed as definite HCC when an extended washout is used. The result that the APASL guideline had the highest pooled sensitivity may also be attributable to the application of HBP hypointensity as an alternative to the washout appearance. These higher sensitivities are particularly valuable in Asian countries, where HCC is highly prevalent, and surgical resection or image-guided ablation is preferred for HCC treatment $[26,27]$. However, the pooled specificity of the definite HCC criteria of KLCA-NCC 2018 was significantly lower than that of the LR-5 or EASL guideline. In the KLCA-NCC 2018 criteria, the specificity inevitably decreased as the sensitivity increased, which is a rather expected result stemming from the fundamental nature of diagnostic test accuracy. However, the pooled specificity of the KLCA-NCC 2018 guideline was significantly higher than that of the APASL guideline as a result of applying size criteria (i.e., $\geq 1 \mathrm{~cm}$ ) and exclusion criteria for HCC, such as targetoid appearance, to exclude common causes of a false-positive diagnosis, including non-HCC malignancy. Consequently, unnecessary treatment or biopsy can be avoided through the application of the KLCA-NCC 2018 rather than the APASL guideline. Overall, we believe that the KLCA-NCC 2018 achieved an appropriate balance between sensitivity-oriented guideline such as the APASL guideline and specificity-oriented guidelines such as the LI-RADS or EASL guidelines and is more optimized for Asian countries than other international guidelines.

In our meta-regression analyses, the type of contrast agent was the only significant factor affecting study heterogeneity. The results revealed that the use of the HBA for MRI showed significantly better sensitivity for definite HCC than the mixed use of ECAs and HBAs, but it also showed lower specificity. The superior sensitivity of HBA-MRI may be attributable to the extended definition of washout, but this high sensitivity comes at the cost of specificity [28]. Although most Asian countries, to improve sensitivity for early detection of HCC, tend to use HBA-MRI more than ECA-MRI for the evaluation of HCC in clinical practice, consideration should be given for an improvement of the low sensitivity of ECA-MRI. As with LI-RADS, it can be optional to adopt additional major imaging features of definite HCC, such as an enhancing capsule and threshold growth In addition, we noted a significant positive correlation between the sensitivity and the false-positive rate (correlation coefficient $=0.667$ ). This result probably indicates that the study heterogeneity was partly due to the threshold effect that occurs when different thresholds or cutoff values are used to determine a positive test result [16]. For example, the included studies applied different washout criteria depending on the type of contrast agent used, and there might be some uncertainty about the definition of ancillary imaging features such as targetoid appearance.

This study has several limitations. First, the number of included studies was small $(n=8)$, as the KLCA-NCC 2018 criteria have only recently been introduced. Second, substantial study heterogeneity was noted regarding sensitivity, which could preclude the creation of robust meta-analytic estimates for diagnostic accuracy. To minimize this limita- 
tion, we investigated its causes and found that the type of contrast agent and the threshold effect significantly influenced study heterogeneity. Third, all included studies originated from South Korea, an area where hepatitis B is endemic, which limits the generalization of our results to other geographic populations with different etiologies of chronic liver disease. However, this geographic homogeneity brought somewhat homogeneous patient cohorts, which may enhance the quality of the evidence provided by this meta-analysis. Given that the KLCA-NCC criteria are focused on the Asian population in an area where hepatitis $\mathrm{B}$ is endemic, our meta-analysis represents the currently available evidence regarding its performance for the diagnosis of HCC.

\section{Conclusions}

In conclusion, the KLCA-NCC 2018 criteria had good overall diagnostic performance with balanced sensitivity and specificity in diagnosing HCC using MRI, even for HCCs smaller than $20 \mathrm{~mm}$. In comparison with the definite HCC category alone, the definite/probable HCC category showed an increase in pooled sensitivity and a decrease in specificity. Substantial study heterogeneity was noted for sensitivity and was significantly associated with the threshold effect and the type of MRI contrast agent. In addition, studies that used HBAs showed significantly higher sensitivity but lower specificity than those that used ECAs to diagnose HCCs.

Supplementary Materials: The following are available online at https:/ /www.mdpi.com/article/10 .3390/diagnostics11101763/s1, Table S1: Search queries, Figure S1: Results of quality assessments of the articles according to the QUADAS-2 criteria, Figure S2: Deeks' funnel plot to evaluate publication bias regarding definite HCC as defined by the KLCA-NCC 2018 imaging criteria, Figure S3: Forest plot of interobserver agreement for categorization of hepatic lesions according to the KLCA-NCC 2018 imaging criteria.

Author Contributions: Conceptualization, D.H.K. and J.-I.C.; Methodology, D.H.K. and J.-I.C.; Software, D.H.K.; Validation, D.H.K. and J.-I.C.; Formal Analysis, D.H.K., B.K., H.K. and J.-I.C.; Data Curation, D.H.K. and B.K.; Writing-Original Draft Preparation, D.H.K.; Writing-Review and Editing, B.K., S.Y.Y., H.K. and J.-I.C.; Supervision, J.-I.C.; Funding Acquisition, J.-I.C. All authors have read and agreed to the published version of the manuscript.

Funding: This work was supported by the National Research Foundation of Korea (NRF) grant funded by the Korea government (MSIT) (grant number: 2019R1F1A1060566).

Institutional Review Board Statement: Ethical review and approval were waived for this study, since it is a systematic review and meta-analysis of previous studies.

Informed Consent Statement: Patient consent was not required for this study, since it is a systematic review and meta-analysis of previous studies.

Data Availability Statement: All data accessed and analyzed in this study are available in the article and its Supplementary Materials.

Acknowledgments: The authors would like to acknowledge Sang Hyun Choi and Jae Ho Byun for providing additional study detail from their prior publication.

Conflicts of Interest: The authors declare no conflict of interest.

\section{References}

1. El-Serag, H.B. Hepatocellular carcinoma. N. Engl. J. Med. 2011, 365, 1118-1127. [CrossRef] [PubMed]

2. Bray, F.; Ferlay, J.; Soerjomataram, I.; Siegel, R.L.; Torre, L.A.; Jemal, A. Global cancer statistics 2018: GLOBOCAN estimates of incidence and mortality worldwide for 36 cancers in 185 countries. CA Cancer J. Clin. 2018, 68, 394-424. [CrossRef]

3. Marrero, J.A.; Kulik, L.M.; Sirlin, C.B.; Zhu, A.X.; Finn, R.S.; Abecassis, M.M.; Roberts, L.R.; Heimbach, J.K. Diagnosis, Staging, and Management of Hepatocellular Carcinoma: 2018 Practice Guidance by the American Association for the Study of Liver Diseases. Hepatology 2018, 68, 723-750. [CrossRef]

4. European Association for the Study of the Liver. EASL Clinical Practice Guidelines: Management of hepatocellular carcinoma. J. Hepatol. 2018, 69, 182-236. [CrossRef] 
5. Korean Liver Cancer Association; National Cancer Center. 2018 Korean Liver Cancer Association-National Cancer Center Korea Practice Guidelines for the Management of Hepatocellular Carcinoma. Korean J. Radiol. 2019, 20, 1042-1113. [CrossRef]

6. Park, J.W. Korean Liver Cancer Study Group and National Cancer Center. Practice guideline for diagnosis and treatment of hepatocellular carcinoma. Korean J. Hepatol. 2004, 10, 88-98.

7. Korean Liver Cancer Study Group and National Cancer Center, Korea. Practice guidelines for management of hepatocellular carcinoma 2009. Korean J. Hepatol. 2009, 15, 391-423. [CrossRef]

8. Korean Liver Cancer Study Group (KLCSG); National Cancer Center, Korea (NCC). 2014 KLCSG-NCC Korea practice guideline for the management of hepatocellular carcinoma. Gut Liver 2015, 9, 267-317.

9. Byun, J.; Choi, S.H.; Byun, J.H.; Lee, S.J.; Kim, S.Y.; Won, H.J.; Shin, Y.M.; Kim, P.N. Comparison of the diagnostic performance of imaging criteria for HCCs $</=3.0 \mathrm{~cm}$ on gadoxetate disodium-enhanced MRI. Hepatol. Int. 2020, 14, 534-543. [CrossRef] [PubMed]

10. Jeon, S.K.; Lee, J.M.; Joo, I.; Yoo, J.; Park, J.Y. Comparison of guidelines for diagnosis of hepatocellular carcinoma using gadoxetic acid-enhanced MRI in transplantation candidates. Eur. Radiol. 2020, 30, 4762-4771. [CrossRef] [PubMed]

11. Hwang, S.H.; Park, M.S.; Park, S.; Lim, J.S.; Kim, S.U.; Park, Y.N. Comparison of the current guidelines for diagnosing hepatocellular carcinoma using gadoxetic acid-enhanced magnetic resonance imaging. Eur. Radiol. 2021, 31, 4492-4503. [CrossRef]

12. Park, S.H.; Shim, Y.S.; Kim, B.; Kim, S.Y.; Kim, Y.S.; Huh, J.; Park, J.H.; Kim, K.W.; Lee, S.S. Retrospective analysis of current guidelines for hepatocellular carcinoma diagnosis on gadoxetic acid-enhanced MRI in at-risk patients. Eur. Radiol. 2021, 31, 4751-4763. [CrossRef]

13. Lee, S.M.; Lee, J.M.; Ahn, S.J.; Kang, H.J.; Yang, H.K.; Yoon, J.H. Diagnostic Performance of 2018 KLCA-NCC Practice Guideline for Hepatocellular Carcinoma on Gadoxetic Acid-Enhanced MRI in Patients with Chronic Hepatitis B or Cirrhosis: Comparison with LI-RADS Version 2018. Korean J. Radiol. 2021, 22, 1066-1076. [CrossRef]

14. Liberati, A.; Altman, D.G.; Tetzlaff, J.; Mulrow, C.; Gøtzsche, P.C.; Ioannidis, J.P.; Clarke, M.; Devereaux, P.J.; Kleijnen, J.; Moher, D. The PRISMA statement for reporting systematic reviews and meta-analyses of studies that evaluate healthcare interventions: Explanation and elaboration. BMJ 2009, 339, b2700. [CrossRef]

15. Whiting, P.F.; Rutjes, A.W.; Westwood, M.E.; Mallett, S.; Deeks, J.J.; Reitsma, J.B.; Leeflang, M.M.; Sterne, J.A.; Bossuyt, P.M.; QUADAS-2 Group. QUADAS-2: A revised tool for the quality assessment of diagnostic accuracy studies. Ann. Intern. Med. 2011, 155, 529-536. [CrossRef] [PubMed]

16. Devillé, W.L.; Buntinx, F.; Bouter, L.M.; Montori, V.M.; De Vet, H.C.; Van der Windt, D.A.; Bezemer, P.D. Conducting systematic reviews of diagnostic studies: Didactic guidelines. BMC Med. Res. Methodol. 2002, 2, 9. [CrossRef] [PubMed]

17. American College of Radiology. CT/MRI Liver Imaging Reporting and Data System Version 2018. Available online: https: // www.acr.org/Clinical-Resources/Reporting-and-Data-Systems/LI-RADS/CT-MRI-LI-RADS-v2018 (accessed on 8 May 2021).

18. Omata, M.; Cheng, A.L.; Kokudo, N.; Kudo, M.; Lee, J.M.; Jia, J.; Tateishi, R.; Han, K.H.; Chawla, Y.K.; Shiina, S.; et al. Asia-Pacific clinical practice guidelines on the management of hepatocellular carcinoma: A 2017 update. Hepatol. Int. 2017, 11, 317-370. [CrossRef]

19. Landis, J.R.; Koch, G.G. The measurement of observer agreement for categorical data. Biometrics 1977, 33, 159-174. [CrossRef]

20. Lee, S.; Kim, S.S.; Chang, D.R.; Kim, H.; Kim, M.J. Comparison of LI-RADS 2018 and KLCA-NCC 2018 for noninvasive diagnosis of hepatocellular carcinoma using magnetic resonance imaging. Clin. Mol. Hepatol. 2020, 26, 340-351. [CrossRef] [PubMed]

21. Lee, S.; Kim, M.J. Validation of the Korean Liver Cancer Association-National Cancer Center 2018 Criteria for the Noninvasive Diagnosis of Hepatocellular Carcinoma Using Magnetic Resonance Imaging. J. Liver Cancer 2020, 20, 120-127. [CrossRef]

22. Kang, H.J.; Lee, J.M.; Yoon, J.H.; Han, J.K. Role of Contrast-Enhanced Ultrasound as a Second-Line Diagnostic Modality in Noninvasive Diagnostic Algorithms for Hepatocellular Carcinoma. Korean J. Radiol. 2021, 22, 354-365. [CrossRef] [PubMed]

23. Kim, D.H.; Choi, S.H.; Kim, S.Y.; Kim, M.J.; Lee, S.S.; Byun, J.H. Gadoxetic Acid-enhanced MRI of Hepatocellular Carcinoma: Value of Washout in Transitional and Hepatobiliary Phases. Radiology 2019, 291, 651-657. [CrossRef] [PubMed]

24. Joo, I.; Lee, J.M.; Lee, D.H.; Jeon, J.H.; Han, J.K. Retrospective validation of a new diagnostic criterion for hepatocellular carcinoma on gadoxetic acid-enhanced MRI: Can hypointensity on the hepatobiliary phase be used as an alternative to washout with the aid of ancillary features? Eur. Radiol. 2019, 29, 1724-1732. [CrossRef] [PubMed]

25. Choi, J.Y.; Lee, J.M.; Sirlin, C.B. CT and MR imaging diagnosis and staging of hepatocellular carcinoma: Part I. Development, growth, and spread: Key pathologic and imaging aspects. Radiology 2014, 272, 635-654. [CrossRef] [PubMed]

26. Kim, D.H.; Choi, S.H.; Park, S.H.; Kim, K.W.; Byun, J.H.; Kim, S.Y.; Lee, S.S.; Shin, Y.M.; Won, H.J.; Kim, P.N. Meta-analysis of the accuracy of Liver Imaging Reporting and Data System category 4 or 5 for diagnosing hepatocellular carcinoma. Gut 2019, 68, 1719-1721. [CrossRef]

27. Fowler, K.J.; Sirlin, C.B. Is It Time to Expand the Definition of Washout Appearance in LI-RADS? Radiology 2019, $291,658-659$. [CrossRef]

28. Kim, S.Y. Diagnosis of hepatocellular carcinoma: Which MRI contrast agent? Which diagnostic criteria? Clin. Mol. Hepatol. 2020, 26, 309-311. [CrossRef] [PubMed] 